\title{
Reversos y rupturas en las movilizaciones contra la desigualdad creciente
}

\author{
Margarita Chaves* \\ Juan Felipe Hoyos García ${ }^{* *}$ \\ Editores asociados de la Revista Colombiana de Antropología \\ Instituto Colombiano de Antropología e Historia (ICANH)
}

DOI: $10.22380 / 2539472 X .1776$

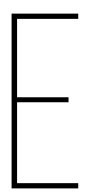

l presente volumen de la Revista Colombiana de Antropología se gestó durante un año marcado por acontecimientos nacionales y globales que han corroborado la dimensión de la crisis epocal que nos fractura como sociedades y como especie. El continuo aumento de la desigualdad, la violación de los derechos humanos, la militarización de las calles y los territorios, la resistencia a abordar los daños al ambiente y a los seres que habitan la Tierra como un proyecto de colaboración mutua se han hecho manifiestos en los impactos sobre el tejido social de una pandemia que deja a la deriva especialmente a los sectores más vulnerables.

La tragedia humana que significa la Covid-19 se tomó el centro de la atención pública con sus millones de fallecidos y enfermos, una recesión económica en ciernes y profundos cambios en nuestra vida cotidiana. Sin embargo, esta grave situación oculta más de lo que revela. Vimos cómo casi desaparecen las vigorosas protestas y denuncias que se desarrollaron durante todo el 2019 en contra de la crisis climática - frente a catástrofes que ponían en evidencia la responsabilidad humana en ellas - y, de igual modo, cómo han sido aplacados por medidas sanitarias y estados de excepción los estallidos sociales en decenas de ciudades de todo el mundo contra regímenes autoritarios. Incluso este volumen, que ha visto la luz gracias al esfuerzo de equipos editoriales confinados, sobrecargados de trabajo y solitarios debido a las medidas de la cuarentena y el distanciamiento social, enfrenta su verdadera crisis por el acorralamiento del modelo mercantil de evaluación y publicación científica.

En este contexto, recibimos también la triste noticia de la temprana partida de David Graeber. Su muerte nos aflige por la pérdida inmensa que representa para la antropología y el análisis social en las actuales circunstancias de desigualdad y atropellos del poder estatal y económico. No podíamos dejar de

\footnotetext{
*_mchaves@icanh.gov.co / https://orcid.org/0000-0002-9015-0680

** jhoyos@icanh.gov.co / https://orcid.org/0000-0001-7179-4360
} 
rendirle un homenaje y es por eso que en la sección “Cuestiones de método" incluimos la traducción al español de su artículo "Revolution in Reverse (or, on the Conflict between Political Ontologies of Violence and Political Ontologies of the Imagination)". Dentro de las distintas y fascinantes propuestas de interpretación de este autor sobre el momento político que atropella la democracia, escogimos este texto por la resonancia que puede tener en Colombia. El descontento de las nuevas ciudadanías ante el brutal asesinato de jóvenes, líderes sociales y excombatientes de la extinta guerrilla de las Fuerzas Armadas Revolucionarias de Colombia - Ejército del Pueblo (FARC-EP) se ha expresado en manifestaciones populares multitudinarias reprimidas por la brutalidad policial que simplifica la complejidad de las soluciones reclamadas al estado ${ }^{1}$. Estas movilizaciones conectan, sin embargo, violencia y formas de la imaginación política sobre las que es necesario reflexionar, tal y como lo propone David Graeber en su ensayo. Además, la sección presenta la versión en español del artículo "David Graeber and the Anthropology of Unequal Society”, escrito por Keith Hart, como complemento a este homenaje.

Este volumen reúne artículos que, pese a llegar por fuera de las convocatorias temáticas, poseen cierta coherencia respecto de las luchas contra las estructuras de desigualdad que nos atraviesan como sociedad. Reflexiona sobre las respuestas que surgen por parte de las bases sociales ante la crisis del multiculturalismo como régimen de representación y garantía de derechos, así como frente al lugar de la reparación como la forma de relacionamiento entre los sujetos y el estado, desde donde reclaman por los incumplimientos de este fallido proyecto y reenmarcan las vulneraciones civiles a la luz de los derechos humanos. Las víctimas y las intermediaciones expertas que las acompañan activan por medio de este tipo de demandas los diversos instrumentos de las justicias transicionales y restaurativas en proceso de consolidación global.

Después de casi tres décadas de multiculturalismo colombiano, dos de los artículos de este volumen se preguntan por las transformaciones tanto de las dinámicas sociales que hicieron posible el reconocimiento de derechos en la diferencia como de las políticas que les dieron sustento. Dest sugiere que, mientras que las posibilidades de inclusión del modelo multicultural se agotan, desde los sujetos de la diferencia surgen apuestas que movilizan políticas del cuidado de la vida lideradas por el poder femenino y de defensa del territorio por las vías de hecho. Cunin, por su parte, plantea que en el escenario posmulticulturalista afrodescendiente se evidencia la movilización del derecho y las redefiniciones

\footnotetext{
1 A lo largo del texto se escribe la palabra estado en minúscula para no reificar el concepto.
} 
del pasado y el presente para poner en juego las categorías de esclavizado o descendiente de esclavos y reclamar el estatus político de víctimas, en un contexto nacional con significativos instrumentos de justicia transicional. Paralelamente, Zenobi, refiriéndose a lo que sucede en Argentina, también pone de presente los límites de las relaciones jurídicas ordinarias entre víctimas y estado, cuando se promueve la reparación por incumplimientos en la protección a través de la movilización de los derechos humanos y las políticas transicionales. En otra clave, pero no menos relevante, otros artículos del volumen abordan categorías de aproximación a otras diversidades. Este es el caso del artículo de Pazos y Giraldo, quienes mediante el ejercicio etnográfico revelan significados de las prácticas homoeróticas en escenarios urbanos de una ciudad intermedia colombiana; el de Patiño y Hernández, que se aproxima a la vida cotidiana de hombres y mujeres esclavizados en el Cauca colonial, una de las regiones colombianas más vibrantes en términos de las manifestaciones de la diversidad étnico-racial; $y$, finalmente, el de Dapuez, que reflexiona sobre un programa argentino de transferencias monetarias condicionadas para jóvenes que deben decidir si plegarse a los requerimientos del programa o ingresar al mercado laboral mediante trabajos no calificados. Veamos qué propone cada uno de ellos en mayor detalle.

El artículo de Anthony Dest, “'Desencantarse del estado’: confrontando los límites del multiculturalismo neoliberal en Colombia”, analiza los planteamientos de los movimientos afro e indígena de la región del norte del Cauca: por una parte, mujeres afrodescendientes que enfrentan la minería ilegal y el narcotráfico mediante redes de cuidado mutuo y del territorio sin el más mínimo apoyo estatal; por otra, el Proceso de Liberación de la Madre Tierra que adelanta una lucha por la recuperación de territorio por las vías de hecho, mientras encara una fuerte represión hacendataria y policial. Ambos movimientos convergen en su resistencia interétnica ante la amenaza del despojo por empresas y actores políticos y económicos poderosos, así como de la violencia de las mafias del narcotráfico y las bandas criminales que operan en el área. Sus líderes y lideresas expresan abiertamente reparos al régimen de incumplimiento de las políticas multiculturales y de integración étnica mediante recursos estatales, y cuestionan el marco de derechos diferenciados que han propiciado la cooptación de los movimientos sociales. Denuncian así la ausencia de justicia redistributiva y de alternativas al estado de cosas.

Los artículos de Cunin y de Zenobi parecieran sugerir que, por la vía de la movilización del derecho, el reconocimiento desemboca en las políticas de reparación. Sin embargo, los casos analizados por ellos se refieren a políticas de 
reparación de naturaleza contrastada, en las que además el multiculturalismo y la justicia transicional intervienen diferencialmente.

Elisabeth Cunin, en su artículo “¿Reparar la esclavitud en Colombia? Movilización del derecho en un contexto multicultural”, examina dos casos en los que el derecho y la intervención de la Corte Constitucional se movilizan con el objeto de poner fin a una injusticia histórica, en ambos casos relacionada con la esclavitud. El primero está referido a la demanda por inconstitucionalidad de una ley del año 1851 sobre la libertad de los esclavos; el segundo, a una acción de tutela para defender un derecho de propiedad colectiva adquirido por una líder afrodescendiente en el marco de la legislación multicultural vigente. Si bien las reivindicaciones utilizan categorías alusivas a la historia, como descendiente de esclavo o esclavizado, son los marcos del multiculturalismo los que permiten establecer las normas legales de reconocimiento de la diferencia de los afrocolombianos en este tipo de procesos jurídicos. Como lo señala la autora, la sustitución de categorías culturales, como afrodescendiente, por categorías históricas, como esclavizado o descendiente de esclavos, genera la superposición de los planos jurídico e histórico y de sus respectivos registros y amplía la dependencia en la intermediación del derecho y de los abogados para hacer efectivo el marco de derechos multiculturales de los sujetos de la diferencia.

Vistos de manera paralela, los artículos de Dest y Cunin generan preguntas tanto de estrategia sobre los objetivos de la movilización política de afrodescendientes e indígenas como de epistemología sobre el papel de los conocimientos locales o la manera de hacer las cosas.

Aunque podría pensarse que en Argentina las reparaciones están relacionadas en su mayoría con los crímenes de las políticas represivas durante la dictadura militar, el artículo de Diego Zenobi, "El sufrimiento como valor: expertise y compromiso en las reparaciones económicas a las víctimas de una 'tragedia' argentina”, nos muestra una faceta diferente de las formas contemporáneas de la reparación. El autor reta las visiones más consolidadas de la teoría social sobre la reparación, entendida como una forma de modelamiento de la condición de víctima, para mostrar que las víctimas y los expertos que las acompañan también les dan forma a esos dispositivos de reparación. En este caso, analiza las demandas de las víctimas de la tragedia de Cromañón, el incendio de un local donde se desarrollaba un concierto de rock en el que murieron casi doscientos jóvenes. Se enfoca en cómo los abogados que representaron a las víctimas, antes que buscar indemnizaciones económicas, activaron el discurso de los derechos humanos y los instrumentos de la justicia transicional para involucrar al estado como responsable. Agencian así configuraciones morales sobre la corrupción y el sufrimiento excepcional de las víctimas para "hacer justicia”. 
Vistos en conjunto, los artículos de Dest, Cunin y Zenobi hacen referencia directa a un cierto desarreglo en las categorías de las políticas que relacionan a los sujetos con el estado. De ahí el papel central que las reparaciones han empezado a asumir como interfase de estas relaciones en los planos simbólico, histórico, económico y político, y de su exigencia de institucionalización en la movilización del derecho. El resultado, si bien disímil, ha terminado por acentuar una juridización de las políticas públicas que corre paralela al surgimiento de un activismo que a la vez renuncia a los marcos del derecho y de las políticas institucionales. Un caso excepcional lo representan las asignaciones monetarias condicionadas como las que promueve el Banco Mundial en el sur global.

En este caso, podríamos afirmar, las políticas estatales dependen y se sostienen por medio de la globalización jerarquizada de programas de ingreso básico ciudadano, cuya universalización se propone hoy como medida urgente para enfrentar el aumento de la desigualdad económica. Sin embargo, la jerarquización de este tipo de medidas redistributivas del ingreso continúa presentando un tremendo diferencial en la manera como se llevan a efecto en los países noratlánticos y del sur global. En el caso que analiza Andrés Dapuez en su artículo "Dinero-capital de la Asignación Universal por Hijo para la Protección Social en un barrio marginal de la ciudad de Paraná, Argentina”, una madre y su hijo se debaten entre la posibilidad de acumular lo que la política denomina capital humano, mediante la permanencia del hijo en el sistema educativo, o la de emplearse como obrero de la construcción y así, a su modo de ver, remediar de manera más eficiente sus cargas económicas. El caso es sugerente en cuanto permite una aproximación al contexto argentino, único país en América Latina donde el estado de bienestar alcanzó algún desarrollo. Dapuez invita a la reflexión sobre lo que sucede cuando la lógica de buscar una mejoría en las condiciones de vida de las mayorías, por medio de la seguridad en el trabajo, cede a las políticas focalizadas, como la de la Asignación Universal por Hijo, que buscan reducir la pobreza a largo plazo por medio del incremento del capital humano mediante pequeñas transferencias condicionadas a la educación en efectivo, es decir, garantizando un ingreso independientemente del trabajo. Las preguntas al respecto están abiertas y las herramientas conceptuales del análisis, en debate.

En "Arqueología e historia de africanos y afrodescendientes en el Cauca, Colombia”, Diógenes Patiño y Martha C. Hernández llevan a cabo un ejercicio de gran relevancia pero poco desarrollado en el país: la arqueología histórica de la esclavitud. Proponen una provechosa interlocución entre la historia, la arqueología y los estudios sobre procesos identitarios de las poblaciones afrocolombianas de la ciudad de Popayán y el norte del departamento del Cauca. Con base en indagaciones de terreno contrastadas con resultados de estudios previos 
sobre la cultura material de poblaciones esclavizadas en Brasil y el sur de Estados Unidos, plantean una identificación de formas y técnicas cerámicas asociadas con asentamientos de esclavos en el departamento del Cauca. En diálogo con la información histórica disponible para esta región, la investigación abre un fértil campo para una discusión académica que potencie los estudios sobre los procesos identitarios y organizativos de las poblaciones afrocolombianas contemporáneas.

"Putos, liberales y arrechos: reflexiones etnográficas sobre el deseo homoerótico entre hombres en una sala de videos porno en Pereira, Colombia” es un artículo que nos lleva por los sugerentes espacios de encuentro homoerótico. Aquí Mateo Pazos y Sebastián Giraldo exploran las categorías sociales que organizan estos espacios y que, a la vez que se liberan de las ataduras heteronormativas, reproducen desigualdades sociales y patrones machistas configurados en la sociedad regional. También nos presentan las prácticas de aproximación y encuentro entre los hombres que visitan estos lugares, dando relevancia al espacio construido y a su historia dentro del proceso de urbanización regional. Cabe destacar varias características de este ejercicio etnográfico. Primero, su carácter autogestionado y al margen de cualquier marco académico institucional. Segundo, la asunción de los autores de su lugar simultáneo como usuarios y etnógrafos de esos espacios de encuentro. Esta autonomía y a la vez implicación del escenario etnográfico no obsta para que mantengan una lectura crítica y teóricamente informada sobre el proceso social que abordan.

Un lugar especial en este volumen ocupa la traducción del artículo de David Graeber que mencionamos al comienzo de esta nota editorial. Con este queremos rendir un homenaje a uno de los más importantes antropólogos de las últimas décadas, que infortunadamente nos dejó hace poco. Graeber deja a su muerte un legado paradigmático en su libro En deuda: una historia alternativa de la economía (Barcelona: Ariel, 2014), el cual, aun después de ser publicado, continuó su evolución al ser retomado por los activistas del movimiento Occupy Wall Street en contra de las cargas financieras del endeudamiento. Al artículo de Graeber lo acompaña la traducción del ensayo de Keith Hart: "David Graber y la antropología de la sociedad desigual” que, publicado originalmente en su página The Memory Bank, está dedicado a comentar esta obra, que tal vez sea la más influyente de la política intelectual de Graeber.

En su participación política, David Graeber combinaba el activismo con la observación académica, y es por eso que es reconocido como un académico activista, un antropólogo insurgente, un internacionalista, profundamente involucrado en los movimientos que sus etnografías exploraban. En "Revolución al revés”, Graeber expone los principios de su anarquismo. Un anarquismo que 
aboga por una izquierda que vaya mas allá de la política electoral y conjugue perspectivas democráticas de pequeña escala y el espíritu asambleario de los movimientos como espacios para consolidar la democracia directa. En este destaca los dos pilares de la acción directa: las capacidades radicales de la imaginación y la necesidad de colocar el cuidado en el centro de cualquier comunidad/ colectividad, que en ningún otro espacio se encuentra más fuertemente establecido que en la esfera doméstica de la que surge la política feminista.

Tal vez sea clave recordar lo que afirmó Marshall Sahlins sobre su experiencia como director de la tesis doctoral de Graeber en la Universidad de Chicago:

¿Cómo supervisarías a un anarquista? David fue el estudiante más creativo que he tenido, constantemente poniendo al revés la sabiduría antropológica convencional, a menudo para mostrar cómo los pueblos ostensiblemente dominados, por sus propios medios, subvirtieron estados, reyes y otras instituciones coercitivas que los afligían para crear enclaves de comunidad autogestionados. El activismo de David y su antropología eran una pieza inseparable. El folleto "Fragmentos de una antropología anarquista” es su manifiesto anarquista. No se trata del lanzamiento de bombas o de la insurrección; se trata de cómo los pueblos de todo el mundo, desde la Amazonia hasta el Congo africano, han creado lentamente asilos de autodeterminación frente a los poderes espectrales o gubernamentales. Abogando así por una reconstrucción global, David se convirtió en muchos sentidos en una persona global en su propio ser. ${ }^{2}$

Queremos agradecer especialmente a Eva Mangieri por todo su trabajo de apoyo en la gestión y coordinación editorial de este volumen; a Bibiana Castro y María Angélica Ospina, por la corrección de estilo; a la investigadora María Teresa Salcedo, quien realizó la edición del artículo "Putos, liberales y arrechos: reflexiones etnográficas sobre el deseo homoerótico entre hombres en una sala de videos porno en Pereira, Colombia” para este volumen; a los evaluadores anónimos de los artículos, por su colaboración oportuna; y, finalmente, a Vladimir Caraballo Acuña, quien acaba de asumir el encargo de ser el editor general de la Revista Colombiana de Antropología. Fuimos muy afortunados por contar con sus revisiones antes de cerrar la edición de este volumen.

2 The New York Review, 5 de septiembre de 2020. Traducción propia. 